\title{
TEM MICROSTRUCTURE AND CHEMICAL COMPOSITION OF TRANSITION ZONE BETWEEN STEEL TUBE AND AN INCONEL 625 WELD OVERLAY COATING PRODUCED BY CMT METHOD
}

\begin{abstract}
The aim of this work was to investigate the microstructure and chemical composition of the transition zone between $16 \mathrm{Mo} 3$ steel and Inconel 625 weld overlay coating produced by the Cold Metal Transfer (CMT) method. Investigations were primarily carried out through transmission electron microscopy (TEM) on thin foils prepared by FIB (Focus Ion Beam).

The chemical analysis demonstrated that the amount of certain elements $(\mathrm{Fe}, \mathrm{Ni}, \mathrm{Cr}, \mathrm{Mo}, \mathrm{Nb})$ in the transition zone between the base material and the weld overlay changes quickly, from the composition of the steel to the composition of the composite zone. STEM and TEM investigations revealed that two areas are clearly visible in the transition zone. In the narrow band close to the fusion boundary where plates are clearly visible and the $M_{\mathrm{s}}$ temperature is higher than room temperature, electron diffraction analyses show reflections of martensite and austenite. Moreover, the crystallographic relations between martensite and austenite can be described by the Kurdjumov-Sachs (K-S) relationship $\{110\}_{\alpha^{\prime}}\left\|\{111\}_{\gamma}<1 \overline{1} 1>_{\alpha^{\prime}}\right\|<1 \overline{10}>_{\gamma}$ ). The microstructure of the part of the transition zone with an $M_{\mathrm{s}}$ temperature lower than room temperature as well as that of the composite zone is austenite. The investigations proved that the width of the martensitic area can be significantly limited by using the CMT technique for weld overlaying.

Keywords: Inconel 625, weld overlay coating, transition zone, martensite, CMT, STEM, TEM
\end{abstract}

\section{Introduction}

Components of waste-to-energy boilers that operate in the most aggressive environments are usually made of unalloyed or low-alloyed steels and, to ensure appropriate resistance to fireside corrosion, are currently weld overlaid by a nickel alloys. The solid-solution strengthened nickel alloy Inconel 625 is widely used for these processes due to its very good resistance to corrosion, good creep resistance and weldability [1,2].

During overlay welding, which is similar to conventional welding, a certain layer of the base material (steel) is melted and then mixed with an overlay metal in the weld pool. Between the base material and the fully mixed weld overlay, a transition zone, often called a partially mixed zone, is formed (Fig. 1). The transition zone is a region where mixing between the base metal and the overlay metal is incomplete. The chemical composition, microstructure and the properties across this zone change roughly from the base to the weld overlay metal $[3,4]$. The width of the transition zone is a function of the chemical composition of the base metal and the overlay metal, weld overlaying method, heat input, as well as the feed rate of the overlay wire [5,6]. Therefore, the width the transition zone is influenced by the choice of weld overlaying method, by limiting the melting of the base material and by the dilution of the overlay metal by the base material. The chemical composition of the weld overlay coating mainly depends on the chemical composition of the overlay metal and moreover on the amount of the melted base material that is subsequently mixed with the overlay metal.

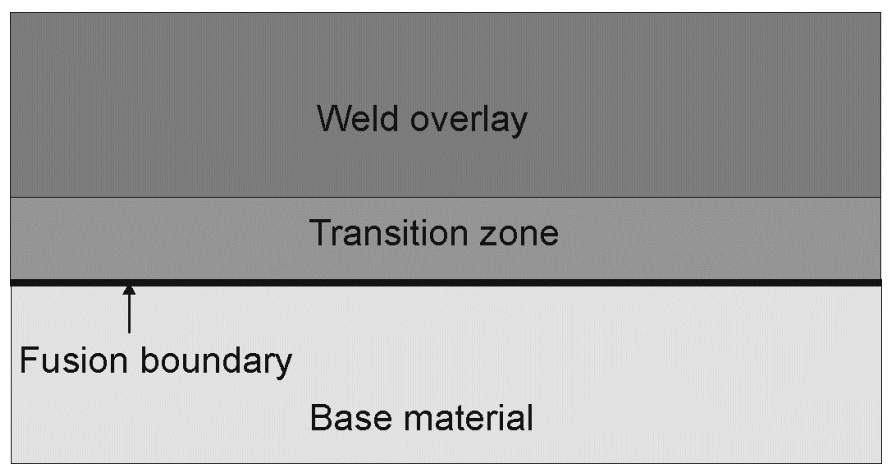

Fig. 1. Microstructural zones in weld overlay coating

Cold Metal Transfer (CMT) is a promising new welding method, characterized by its low heat input compared to conventional techniques. The process was developed in 2002 by Fronius; it is a kind of arc welding with pulse wire feeding. In the CMT process the wire is moved towards the workpiece until an electric short circuit occurs. At that moment the wire is then pulled back. When the short circuit disappears, the wire motion is reversed and again the wire moves towards the workpiece

\footnotetext{
AGH UNIVERSITY OF SCIENCE AND TECHNOLOGY,FACULTY OF METALS ENGINEERING AND INDUSTRIAL COMPUTER SCIENCE, AL. MICKIEWICZA 30, 30-059 KRAKOW, POLAND

* Corresponding author: rozmus@agh.edu.pl
} 
and the process repeats. The heat input directed into the base material can be controlled more accurately in CMT than in other welding methods. Also, overlay welding occurs at a low current. This results in a substantial reduction in heat generation during the CMT welding. This, in turn, makes it possible to limit the thickness of the melted base metal and the dissolution of the base metal in the overlay metal $[7,8]$.

According to the Schaeffler diagram, when a Ni-base alloy is used to clad low-alloyed ferritic steel, between the weld overlay and the steel, martensite should form in the transition zone close to the base material. The presence of martensite within the transition zone is highly undesirable because it is a potential location for hydrogen induced cracking $[9,10]$. The martensite forms only if the $M_{\mathrm{s}}$ (martensite start temperature) is higher than room temperature. Because $M_{\mathrm{s}}$ highly depends on the chemical composition, the thickness of the zone where martensite forms depends on the composition gradient. DuPont et. al. showed that when Inconel 625 and 309L steel were deposited onto low-alloyed steel by electroslag welding performed under similar conditions, the layer thickness where martensite forms was only $1-3 \mu \mathrm{m}$ in the case of the Inconel 625 , and even tens of microns in the case of the 309L steel $[4,6]$. The difference in these martensite layer thicknesses in the two materials results from the higher $\mathrm{Ni}$ and smaller Fe concentration in Inconel 625 compared to the 309L steel. The composition gradient is higher in the case when a Ni-base alloy is used to weld overlay lowalloyed steel rather than 309L steel.

The aim of this work was to investigate the microstructure and chemical composition of the transition zone between $16 \mathrm{Mo} 3$ steel (base metal) and Inconel 625 weld overlay coating produced by CMT. The microstructural zones of a weld overlay (i.e. composite zone, transition zone and heat-affected zone) and analyses of chemical composition of particular areas of the weld overlay that were carried out on metallographic samples with the scanning electron microscope (SEM) equipped with an EDS detector are discuss in separate papers [16,17]. Microsegregations of the chemical composition that are formed during solidification of weld overlay coatings are described in ref. [18,19]. In this work, the investigations of the transition zone were primarily carried out by transmission electron microscopy (TEM) on thin foils prepared by FIB (Focus Ion Beam). Though the microstructure of the transition zone between Inconel 625 overlaid on steel has been already described in the literature [3-6,11-15], those investigations pertained to Inconel 625 coatings produced by arc welding methods like gas metal arc welding (GMAW). There are no thorough studies concerning microstructure and chemical composition of a transition zone in weld overlay coating produced by CMT.

\section{Material and experimental procedure}

The investigations were carried out on Inconel 625 weld overlay coatings on $16 \mathrm{Mo} 3$ steel boiler tubes. Coatings were produced by circumferential overlay welding by the Cold Metal
Transfer (CMT) method. The solid-solution strengthened Inconel 625 alloy in the form of $1 \mathrm{~mm}$ diameter wire was used for overlay welding. The chemical compositions of Inconel 625 and 16Mo3 steel are given in Tables 1 and 2 respectively.

TABLE 1

Chemical composition of Inconel 625 wire, wt. \%

\begin{tabular}{|c|c|c|c|c|c|c|c|c|c|}
\hline \hline Alloy & $\mathbf{C r}$ & $\mathbf{M o}$ & $\mathbf{~ N b}$ & $\mathbf{F e}$ & $\mathbf{M n}$ & $\mathbf{S i}$ & $\mathbf{A l}$ & $\mathbf{C}$ & $\mathbf{N i}$ \\
\hline $\begin{array}{c}\text { Inconel } \\
625\end{array}$ & 22.24 & 9.14 & 3.46 & 0.31 & 0.01 & 0.07 & 0.07 & 0.02 & balance \\
\hline
\end{tabular}

TABLE 2

Chemical composition of $16 \mathrm{Mo} 3$ steel, wt. \%

\begin{tabular}{|c|c|c|c|c|c|c|c|}
\hline \hline Steel & $\mathbf{C}$ & $\mathbf{S i}$ & $\mathbf{M n}$ & $\mathbf{C r}$ & $\mathbf{M o}$ & $\mathbf{N i}$ & $\mathbf{F e}$ \\
\hline $16 \mathrm{Mo} 3$ & 0.16 & 0.34 & 0.65 & 0.30 & 0.30 & 0.30 & balance \\
\hline
\end{tabular}

The investigations of the microstructure and chemical composition of the transition zone were performed with a TECNAI GF20 transmission electron microscope, equipped with a HAADF detector for scanning-transmission technique (STEM) as well as EDAX X-ray spectrometer for the chemical analysis. Phases identification was performed by electron diffraction method (SAED, TEM). TEM specimens prepared by FIB (Focus Ion Beam) were excised from a tube cross-section parallel to the axis and perpendicular to the tube surface. The thin foils encompassed an area around the fusion boundary both in the steel (few $\mu \mathrm{m}$ ) as well as in the weld overlay (tens of $\mu \mathrm{m}$ ).

Chemical composition analyses in the transition zone were performed along straight lines, perpendicular to the fusion boundary. Moreover, along $1000 \mathrm{~nm}$ and $900 \mathrm{~nm}$ length lines, perpendicular to the fusion boundary, qualitative and quantitative point analyses were performed by means of X-ray spectroscopy with energy dispersion (TEM/EDS). The distance between points was $10 \mathrm{~nm}$. The results of point analyses were used to construct diagrams showing the distribution of the selected elements: $\mathrm{Ni}$, $\mathrm{Cr}$ and $\mathrm{Fe}$ (wt \%) - as a function of measuring distance as well as for calculations of the $M_{\mathrm{s}}$ temperature and to construct diagrams showing the changes in $M_{S}$ as a function of measuring distance.

\section{Results and discussion}

The microstructure of a weld overlay coating (SEM) around the fusion boundary, with marked areas, from which thin foils for TEM examinations were excised is presented in Fig. 2. The results of chemical composition analysis along the line perpendicular to the fusion boundary and the microstructure of this area are given in Fig. 3. The microstructure of the weld overlay coating (STEM) with the lines perpendicular to the fusion boundary, along which point analyses of the chemical composition were performed is presented in Fig. 4. The figure also contains diagrams presenting the distributions of the $\mathrm{Ni}, \mathrm{Cr}$ and $\mathrm{Fe}$ (wt. \%) as a function of measuring distance (the diagrams were prepared on the basis of the above-mentioned point analyses). 


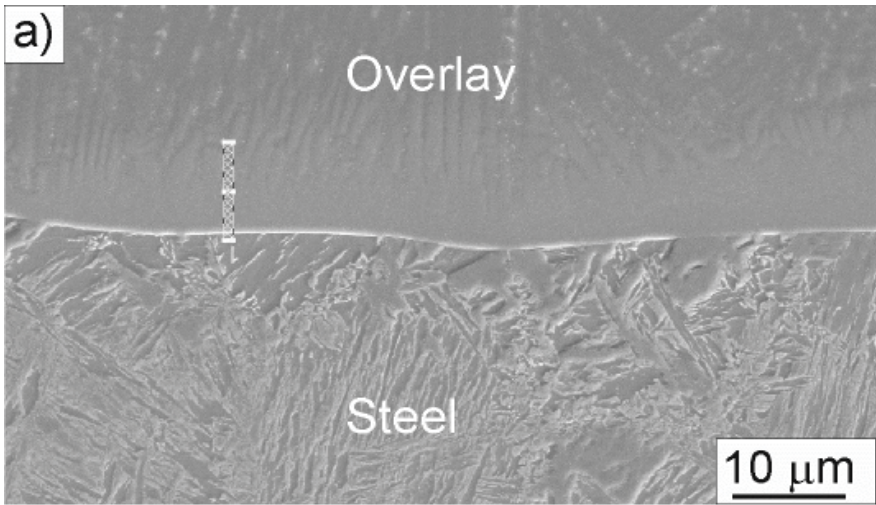

b)

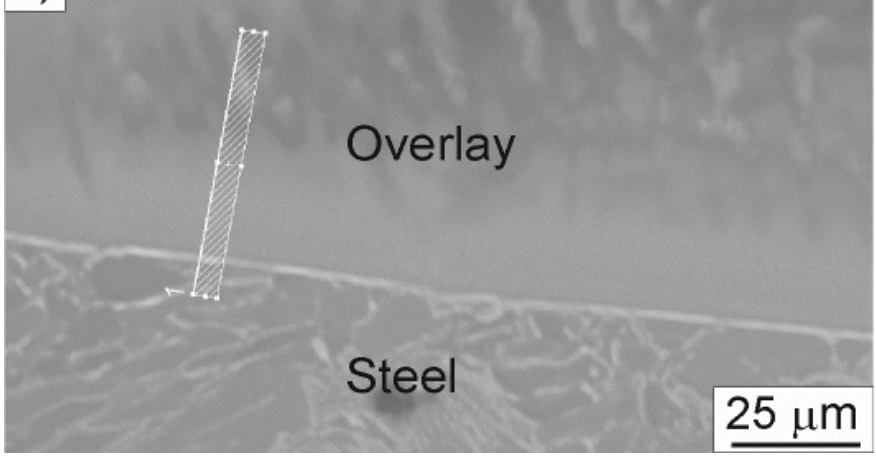

Fig. 2. Microstructure of a weld overlay (SEM) with marked areas from which thin foils for TEM examinations were excised

The chemical analysis along the line perpendicular to the fusion boundary that comprised the base material (steel) and the weld overlay indicate evident that the amount of certain elements in the transition zone between the substrate and the weld overlay changes quickly, from the composition of the steel to the composition of the composite zone (Fig. 3). The content of Fe decreases in the direction from the steel towards the coating, while the amounts of $\mathrm{Ni}, \mathrm{Cr}, \mathrm{Mo}$ and $\mathrm{Nb}$ increase. The transition zone, i.e. the zone where the content of $\mathrm{Ni}, \mathrm{Cr}$, Mo and $\mathrm{Nb}$ increases and the amount of Fe decreases, is about $2.5 \mu \mathrm{m}$; however, a sudden change in the chemical composition occurs close to the fusion boundary (Fig. 3). At a distance 2,5 $\mu \mathrm{m}$ from the fusion boundary up to the coating surface, the content of the aforementioned elements does not undergo significant changes. The analysis of the weld overlay microstructure by scanning transmission electron microscopy (STEM) revealed that between the steel and the weld overlay (within the transition zone) two areas are clearly visible. One is a light area, directly adjacent to the substrate material (marked with " 1 " in Fig. 4), and the other one is a darker area located on the side of the weld overlay and directly adjacent to area 1 (marked with " 2 " in Fig. 4). Point analyses of the chemical composition carried out along $1000 \mathrm{~nm}$ long lines (Fig. 4a, marked as "analysis I") and $900 \mathrm{~nm}$ long lines (Fig. 4b, marked as "analysis II") indicated that a sudden change of the chemical composition occurs in areas 1 and 2. The content of certain elements at the points that correspond to boundaries between given areas of the transition zone (Fig. 4, points A,B and C) are similar in both analyses (Tables 3 and 4). Within the quantitative analysis, the content of all elements

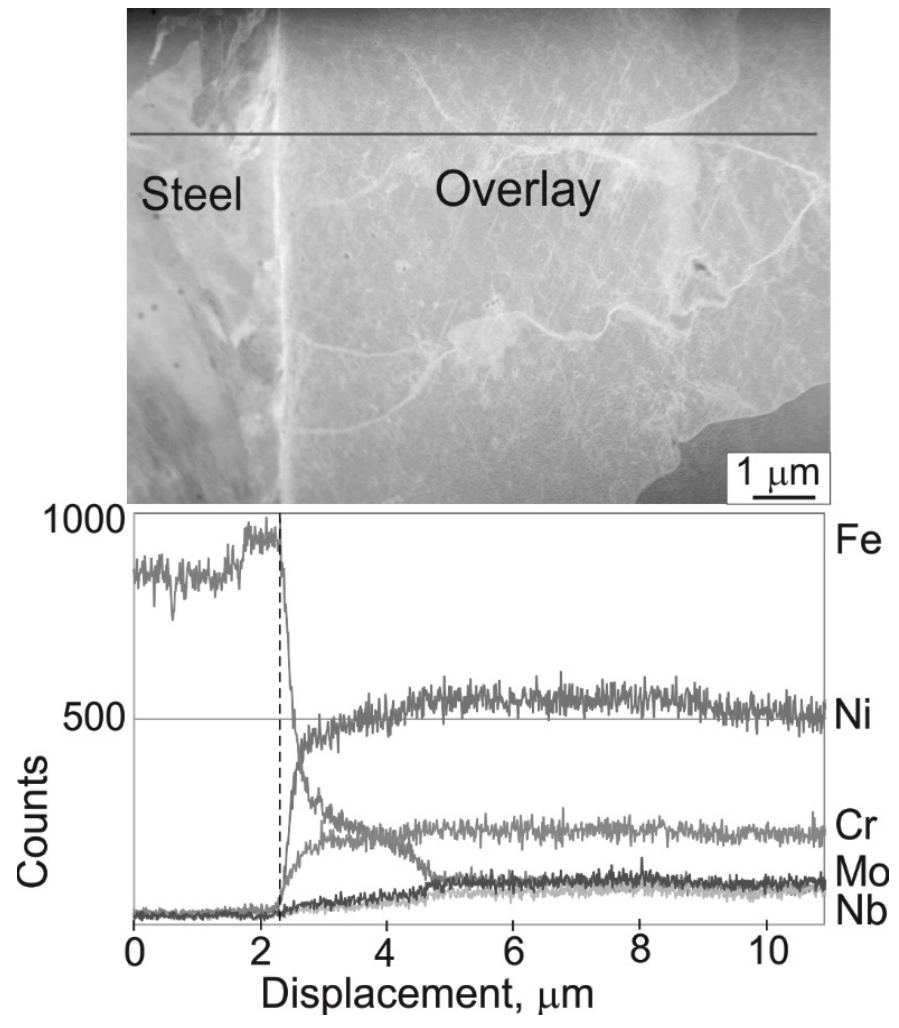

Fig. 3. Microstructure of a weld overlay (STEM) and the composition profile of the $\mathrm{Ni}, \mathrm{Cr}, \mathrm{Mo}, \mathrm{Nb}, \mathrm{Fe}$ (counts) along the marked line

subjected to analysis was normalized to $100 \%$. The tables do not present the percentage share of $\mathrm{Nb}$ and $\mathrm{Mo}$, as their content in the above-identified areas is relatively low. The most notable changes in chemical composition occur in area 2 . Between points $\mathrm{B}$ and $\mathrm{C}$, the content of $\mathrm{Fe}$ decreases by $17.2 \%$ and $17.9 \%$, while the amount of $\mathrm{Ni}$ increases by $15.6 \%$ and $15.8 \%$, according to the analyses given in Fig. $4 a$ and $4 b$, respectively.

TABLE 3

Content of elements $\mathrm{Cr}, \mathrm{Fe}, \mathrm{Ni}$ at the points: $\mathrm{A}, \mathrm{B}, \mathrm{C}$ (analyse I) (wt. \%)

\begin{tabular}{|c|c|c|c|}
\hline \hline \multicolumn{4}{|c|}{ Line $\mathbf{1 0 0 0} \mathbf{~ n m}$} \\
\hline Point & A & B & C \\
\hline $\mathrm{Cr}$ & 1.3 & 5.0 & 6.9 \\
\hline $\mathrm{Fe}$ & 97.1 & 84.0 & 66.8 \\
\hline $\mathrm{Ni}$ & 0.3 & 9.9 & 25.5 \\
\hline
\end{tabular}

TABLE 4

Content of elements $\mathrm{Cr}, \mathrm{Fe}, \mathrm{Ni}$ at the points: $\mathrm{A}, \mathrm{B}, \mathrm{C}$ (analyse II) (wt. \%)

\begin{tabular}{|c|c|c|c|}
\hline \hline \multicolumn{4}{|c|}{ Line 900 nm } \\
\hline & A & B & C \\
\hline $\mathrm{Cr}$ & 1.0 & 5.8 & 7.8 \\
\hline $\mathrm{Fe}$ & 97.9 & 82.7 & 64.8 \\
\hline $\mathrm{Ni}$ & 0.1 & 10.4 & 26.2 \\
\hline
\end{tabular}

The $M_{\mathrm{s}}$ temperature was calculated from the following formula: $M_{\mathrm{S}}\left({ }^{\circ} \mathrm{C}\right)=540-(497 \mathrm{C}+6.3 \mathrm{Mn}+36.3 \mathrm{Ni}+10.8 \mathrm{Cr}+$ $46.6 \mathrm{Mo}$ ), where the symbols of chemical elements refer to their 


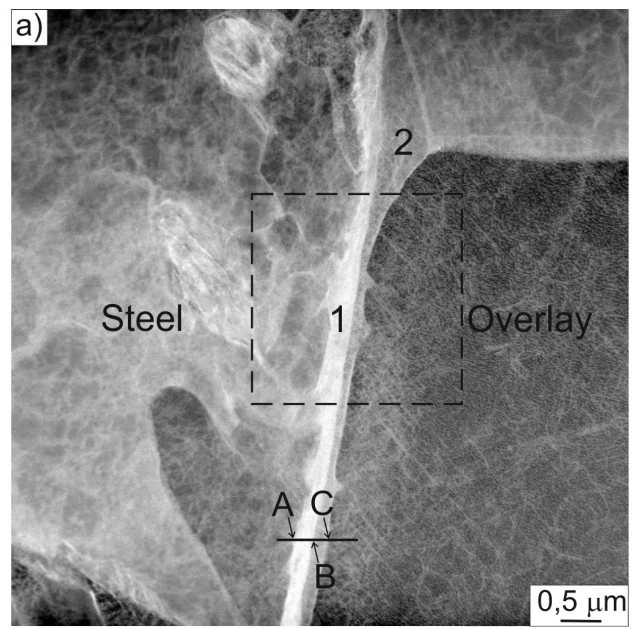

A

B

C

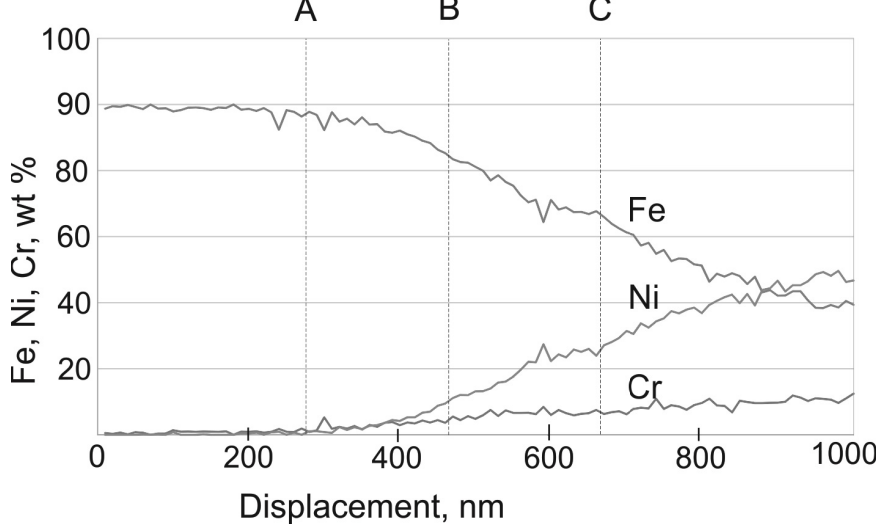

Fig. 4a. Microstructure of a weld overlay (STEM) and the composition profile of the $\mathrm{Ni}, \mathrm{Cr}, \mathrm{Fe}(\mathrm{wt} \%$ ) along the marked line (the dashed line indicates the area presented on Fig. 4b)

content in wt. \% [6]. Because the contents of $\mathrm{C}$ and $\mathrm{Mn}$ were not analysed ( $\mathrm{C}$ belongs to light elements, while the amount of $\mathrm{Mn}$ both in steel and in alloy 625 is rather low (Table 1 and 2)), it was assumed that the changes in both $\mathrm{C}$ and $\mathrm{Mn}$ content in the transition zone are proportional to the changes in the content of the analysed element, simplifying the calculations. $M_{\mathrm{S}}$ temperatures as a function of measuring distance were determined for these areas of the transition zone, where the calculated $M_{\mathrm{s}}$ was higher than room temperature (Fig. 5a and 5b). It follows from these calculations that the $M_{\mathrm{s}}$ temperature decreases suddenly, once the fusion boundary is crossed (Fig. 5a and 5b). At point $\mathrm{B}$, corresponding to the boundary between areas 1 and 2, the $M_{\mathrm{s}}$ temperature is equal to $5^{\circ} \mathrm{C}$ and $25^{\circ} \mathrm{C}$ in analyses I and II, respectively. The width of the area where $M_{\mathrm{s}}$ temperature is higher than room temperature (Fig. 5) corresponds to the distance between points A and B in Fig. 4a and 4b, and it is equal to $190 \mathrm{~nm}$ and $290 \mathrm{~nm}$ in analyses I and II, respectively.

Microstructural examinations performed by TEM revealed that the region within the transition zone where the sudden change in the chemical composition occurs is visible as a light narrow band in STEM images at lower magnification (Fig. 3) and it breaks down into two bands at higher magnification (Fig. 4). This region of the transition zone appears as a black area in TEM micrographs at lower magnification and resembles a line that
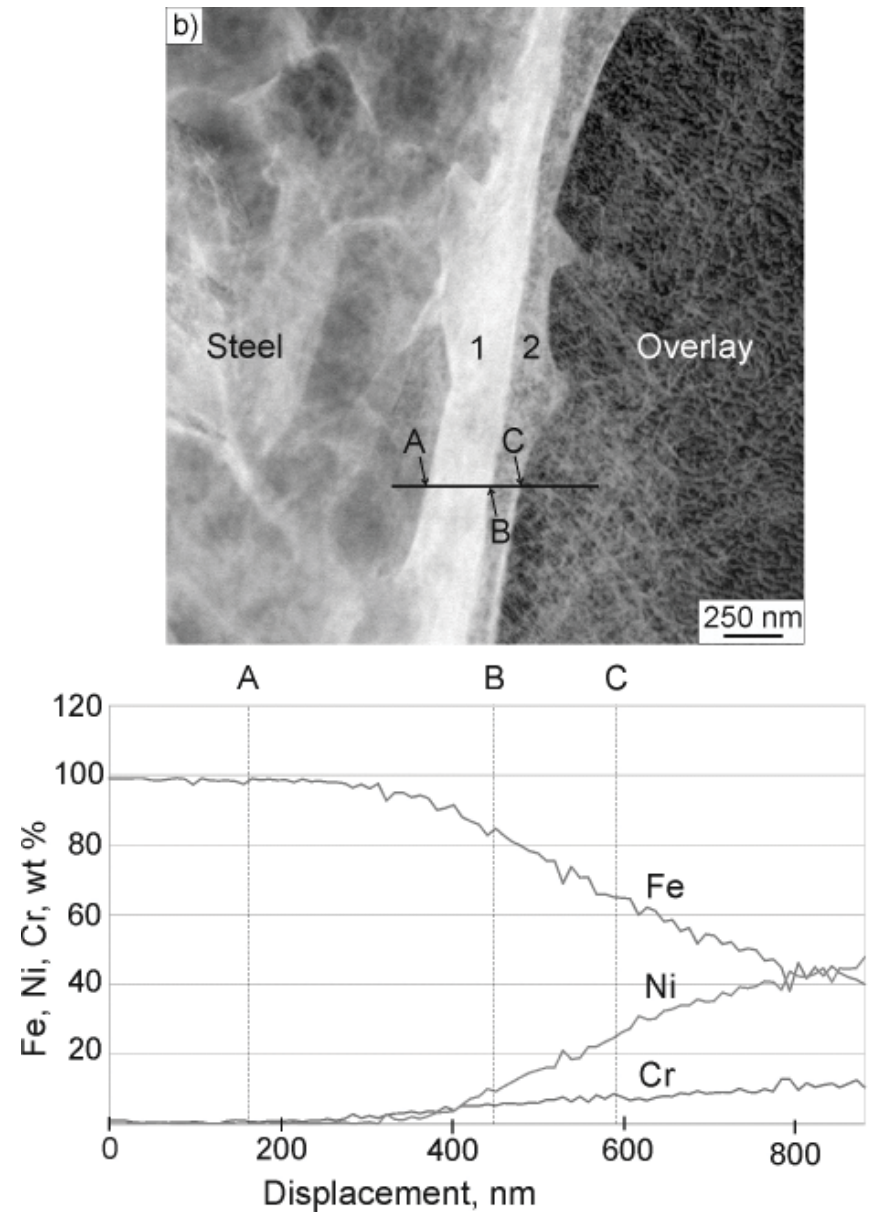

Fig. 4b. Microstructure of the weld overlay (STEM) and the composition profile of the $\mathrm{Ni}, \mathrm{Cr}, \mathrm{Fe}(\mathrm{wt} \%$ ) along the marked line

clearly separates the weld overlay from the substrate (Fig. 6). At higher magnification, both TEM micrographs (Fig. 7a and 7b) and STEM micrographs (Fig. 4a and 4b) show two bands in the transition zone, marked in Fig. 7a and $7 \mathrm{~b}$ as " 1 " and "2", respectively, just as in Fig. 4. The microstructure of band 1 clearly differs from the microstructure of its surroundings. In area 1 plates are clearly visible, and in the surroundings they are not (Fig. 7a and 7b).

Simultaneously, in the band with plates, the $M_{\mathrm{s}}$ temperature is higher than room temperature (band 1). Therefore, one can conclude that martensite is formed in this area. Electron diffraction analyses from the narrow band adjacent to the fusion boundary (area 1) show reflections of martensite $\left(\alpha^{\prime}\right)$ and austenite $(\gamma)$ (Fig. 7c). Moreover, it was pointed out that the crystallographic relation between martensite and austenite can be described by the Kurdjumov-Sachs (K-S) relationship $\{110\}_{\alpha^{\prime}} \|\{111\}_{\gamma}<1 \overline{1} 1>_{\alpha^{\prime}}$ $\|<1 \overline{1} 0>_{\gamma}$ ) (Fig. 7c). Additionally, during the analysis of the microstructure within the transition zone the Schaeffler diagram was used (Fig. 8). The calculated values of chromium $\left(\mathrm{Cr}_{\mathrm{E}}\right)$ and nickel $\left(\mathrm{Ni}_{\mathrm{E}}\right)$ equivalents were the following $\mathrm{Cr}_{\mathrm{E}}=33.2 \%$ and $\mathrm{Ni}_{\mathrm{E}}=65.3 \%$ for the Inconel 625 alloy, and $\mathrm{Cr}_{\mathrm{E}}=0.6 \%$ and $\mathrm{Ni}_{\text {equ }}=5.5 \%$ for $16 \mathrm{Mo} 3$ steel. The point that corresponds to the equivalents for steel is marked in the diagram. A heavy line that ends with an arrow at the upper end (Fig. 8) is drawn from this 

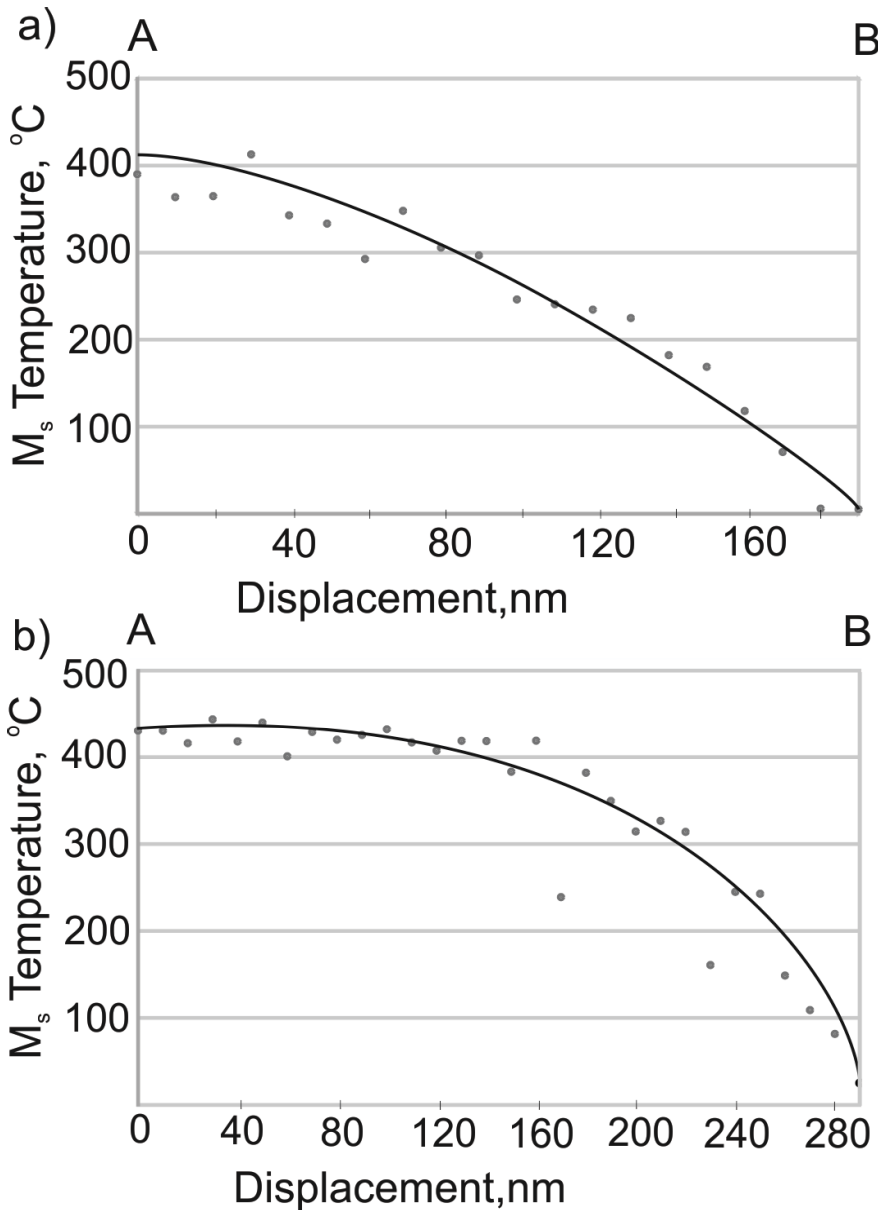

Fig. 5. $M_{s}$ temperature across the area A-B: analyse 1(a), analyse 2(b)

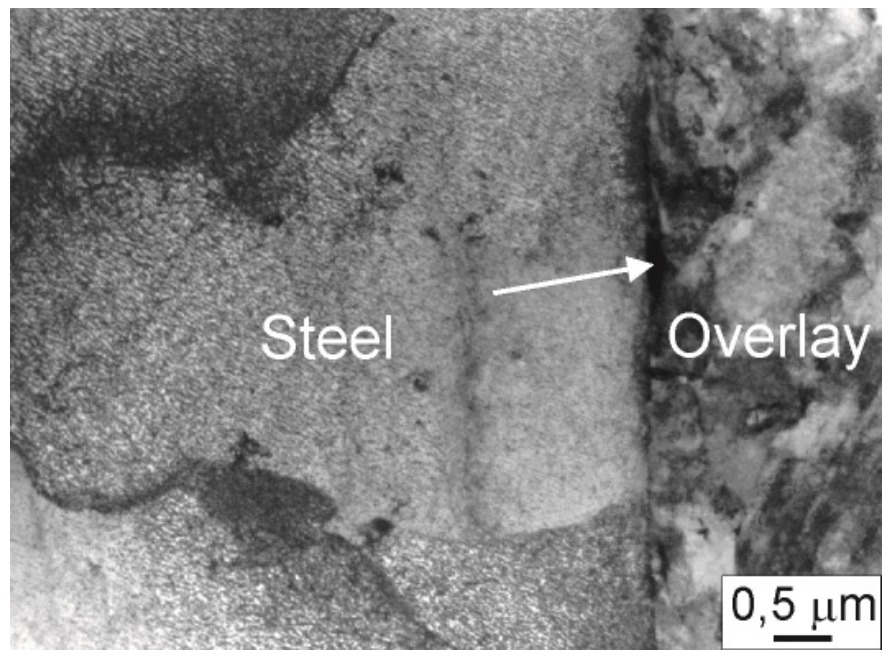

Fig. 6. Microstructure of a weld overlay (TEM), an arrow indicates the transition zone

point on, in the direction to the point corresponding to the values of equivalents determined for the Inconel 625 alloy (located outside the diagram). This line indicates that martensite should form right by the fusion boundary in the transition zone of weld overlays, which agrees with the acquired research results. In band 2, where the $M_{\mathrm{s}}$ temperature is below room temperature as in the case of the composite zone, austenite remains, which was confirmed by electron diffractions (Fig. 7d, Fig. 7e). The change of greyscale in the TEM and STEM images between band 2 and the remaining part of the weld overlay probably
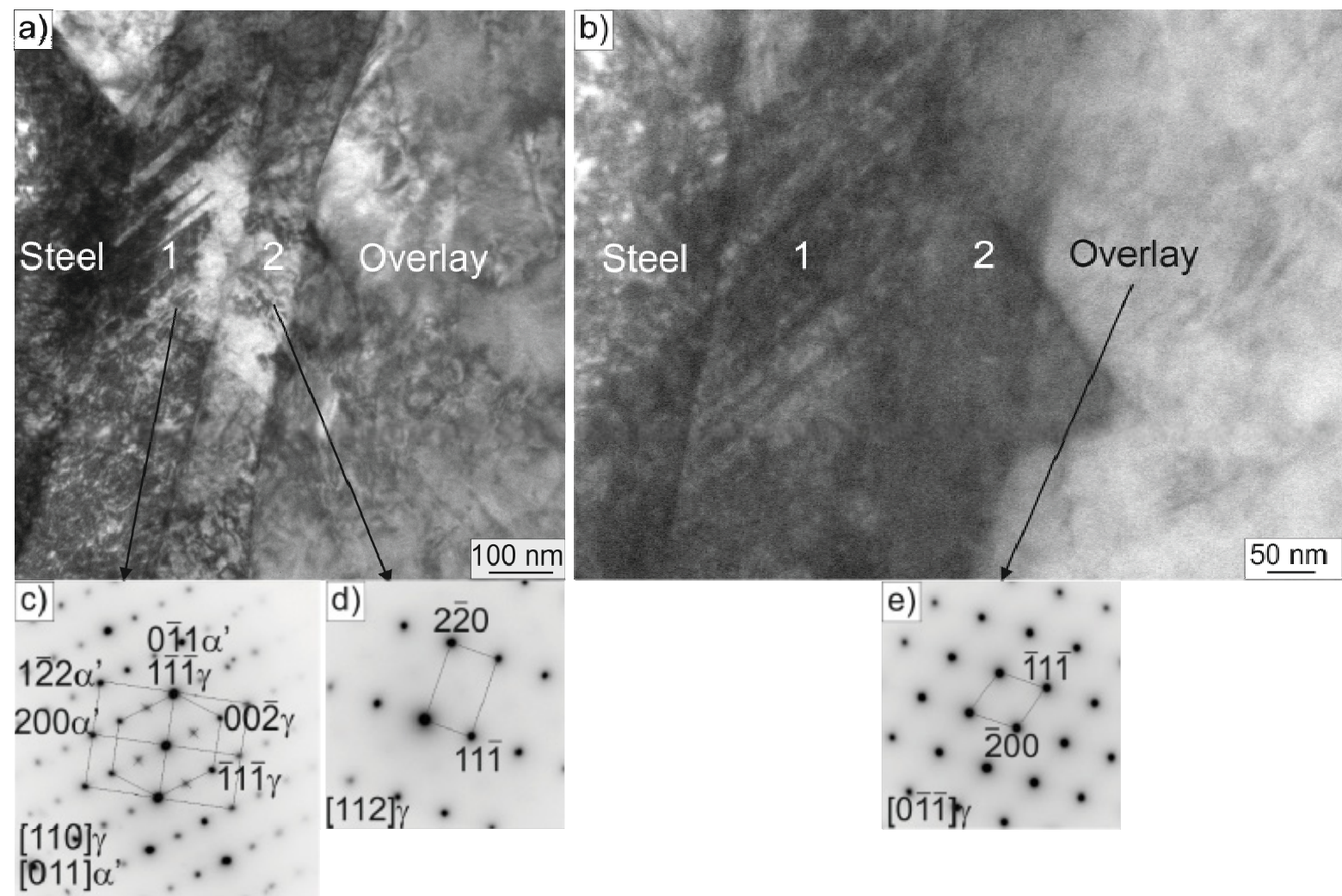

Fig. 7. TEM microstructure of the transition zone $(\mathrm{a}, \mathrm{b})$ and the corresponding diffraction patterns (c) - martensite and austenite (extra spots indicated by $\mathrm{x}$ are double diffraction spots); (d) - austenite; (e) - austenite 
stems from the difference in the chemical composition of these areas, because - as mentioned above - area 2 is an area of the transition zone, where one can observe the greatest change in chemical composition.

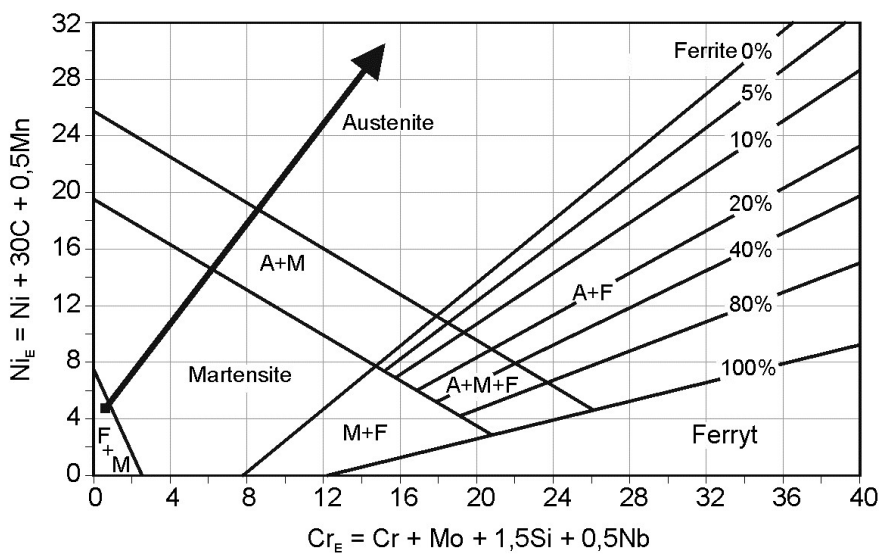

Fig. 8. Schaeffler diagram used for the prediction of microstructure for the transition zone between Inconel 625 and $16 \mathrm{Mo} 3$ steel

The width of the band where martensite forms in the CMT weld overlays under examination is small and does not exceed 190 and $290 \mathrm{~nm}$ in analyses I and II, respectively. The presence of martensite in the transition zone is undesirable, therefore the width of this area should preferably be as small as possible. Appearance of martensite in the transition zone of weld overlays made of Ni alloys deposited by a variety of overlay welding methods on an unalloyed or low-alloy steel is widely discussed in relevant publications [3-6,11-14], and rather unavoidable according to the Schaeffler diagram [20]. The authors of this text, however, are not aware of publications that would discuss and prove the presence and width of the martensite area in weld overlays made of Inconel 625 deposited by the CMT method. DuPont and Kusko examined weld overlays made of alloy 625 and austenitic stainless steel 309L, overlaid by the electroslag welding method on low-alloy steel [6]. The width of the transition zone where martensite was formed amounted to $2-3 \mu \mathrm{m}$ in the case of overlaying alloy 625 , and $35-39 \mu \mathrm{m}$ in the case of 309L steel. The presence of about $20 \mu \mathrm{m}$ wide martensitic area in weld overlays made of Alloy 52 deposited by the GTAW method was documented by Chung by means of scanning electron microscopy [21]. Apart from this, investigations of the transition zone of weld overlays made of Inconel 82 were carried out by Chen [22]. In this case, the method of overlaying was not identified, but the width of the martensitic area amounted to a few $\mu \mathrm{m}$. The width of the martensite zone could be highly limited by using CMT technique for overlay welding. The CMT method introduces low amounts of heat compared to traditional overlaying methods. This method considerably reduces the width of the melted base material and the dissolution of the base metal in the weld overlay compared to common arc welding methods. Similarly, the width of the martensitic area in the transition zone of weld overlays is considerably limited in weld overlays made by this method.

\section{Conclusions} The amount of certain elements $(\mathrm{Fe}, \mathrm{Ni}, \mathrm{Cr}, \mathrm{Mo}, \mathrm{Nb})$ in the transition zone between the base material and the weld overlay changes sharply, from the composition of the steel to the composition of the composite zone.

- There are two bands clearly visible in the transition zone. The narrow band close to the fusion boundary where the $M_{\mathrm{s}}$ temperature is higher than room temperature is composed of martensite and austenite.

- The crystallographic relation between martensite and austenite can be described by the Kurdjumov-Sachs (K-S) relationship $\{110\}_{\alpha^{\prime}}\left\|\{111\}_{\gamma}<1 \overline{1} 1>_{\alpha^{\prime}}\right\|<1 \overline{1} 0>_{\gamma}$ ).

- In the area of the transition zone, where the $M_{\mathrm{s}}$ temperature is lower than room temperature as in the case of composite zone, austenite remains.

- The width of the band where martensite is formed could be highly limited by using CMT technique for weld overlaying.

\section{Acknowledgements}

The investigations were financed by the AGH University of Science and Technology project 11.11.110.295

\section{REFERENCES}

[1] X. Xing, X. Di, B. Wang, The effect of post-weld heat treatment temperature on the microstructure of Inconel 625 deposited metal, J. Alloys Compd. 593, 110-116 (2014).

[2] S.A. David, J.A. Siefert, J.N. DuPont, J.P. Shingledecker, Weldabillity and weld performance of candidate nickel base superalloys for advanced ultrasupercritical fossil power plants part I: fundamentals, Sci. Technol. Weld. Joining. 7, 532-550 (2015).

[3] J.C. Lippold, Welding Metallurgy and Weldability, A John Wiley \& Sons, Inc, New Jersey, 2015.

[4] J.N. DuPont, J.C. Lippold, S.D. Kiser, Welding Metallurgy and Weldability of Nickel-Base Alloys, A John Wiley \& Sons, INC., Publication, 2009.

[5] J.N. DuPont, Microstructural evolution and high temperature failure of ferritic to austenitic dissimilar welds, Int. Mater. Rev. 4, 208-232 (2012).

[6] J.N. DuPont, C.S. Kusko, Technical Note: Martensite formation in austenitic/ferritic dissimilar alloy welds, Weld. J. 51-54 (2007).

[7] J. Feng, H. Zhang, P. He, The CMT short-circuiting metal transfer process and its use in thin aluminium sheets welding, Mater. Des. 30, 1850-1852 (2009).

[8] C.G. Pickin, S.W. Williams, M. Lunt, Characterisation of the cold metal transfer (CMT) process and its application for low dilution cladding. J. Mater. Process. Technol. 211, 496-502 (2011).

[9] N. Eliaz, A. Shachar, B. Tal, D. Eliezer, Characteristic of hydrogen embrittlement, stress corrosion cracking and tempered martensite embrittlement in high-strength steels, Eng. Fail. Anal. 9, 167-184 (2002). 
[10] M.D. Rowe, T.W. Nelson, J.C. Lippold, Hydrogen-induced cracking along the fusion boundary of dissimilar metal welds, Weld. J., 31-37 (1999).

[11] A.A. Omar, Effects of welding parameters on hard zone formation at dissimilar metal welds, Research Developments, 86-93 (1998).

[12] B. Zhihui Wang, B. Xu, C. YE, Study of the martensite structure at the weld interface and the fracture toughness of dissimilar metal joints, Weld. Res. Suppl. 397-402 (1993).

[13] C.C. Silva, H.C. de Miranda, M.F. Motta, J.P Farias, Influence of welding in operational conditions on the partial mixed zone formation in Ni-based dissimilar weld overlay, Trends in welding research, The Materials Information Society pp. 336-344, 2012.

[14] B.T. Alexandrov, J.C. Lippold, J.W. Sowards, a. T. Hope, D.R. Saltzmann, Fusion boundary microstructure evolution associated with embrittlement of Ni-base alloy overlays applied to carbon steel, Weld World 57, 39-53 (2012).

[15] G. Li, J. Huang, Y. Wu, An investigation on microstructure and properties of dissimilar welded Inconel 625 and SUS 304 using high-power $\mathrm{CO}_{2}$ laser, Int. J. Adv. Manuf. Technol. 76, 1203-1214 (2015).
[16] M. Rozmus-Górnikowska, M. Blicharski, J. Kusiński, L. Kusiński, M. Marszycki, Influence of boiler pipe cladding techniques on their microstructure and properties. Arch. Metall. Mater. 58, 1993-1996 (2013).

[17] M. Rozmus-Górnikowska, M. Blicharski, J. Kusiński, Metalic Materials 52, 141-147 (2014).

[18] M. Rozmus-Górnikowska, Ł. Cieniek, M. Blicharski, J. Kusiński, Microstructure and microsegregation of an Inconel 625 weld overlay produced on steel pipes by The Cold Metal Transfer technique. Arch. Metall. Mater. 59, 1081-1084. (2014).

[19] M. Rozmus-Górnikowska, M. Blicharski, Microsegregation and precipitates in Inconel 625 arc weld overlay coatings on boiler pipes, Arch. Metall. Mater. 60, 2599-2605 (2015).

[20] B. Mvola, P. Kah, J. Martikainen, Dissimilar ferrous metal welding using advanced gas metal arc welding proceses, Rev. Adv. Mater. Sci. 38,125-137 (2014).

[21] W. Chung, J. Huang. L. Tsay, Ch. Chen, Microstructure and stress corrosion cracking behaviour of the weld metal in alloy 52-A508 dissimilar welds, Mater. Trans. 52, 12-19 (2011).

[22] Z R. Chen, Y.H. Lu, TEM observations of martensite layer at the weld interface of an A508III to Inconel 82 dissimilar metal weld joint, Metall. Mater. Trans. A 46, 5494-5498 (2015). 